\title{
Microbial biogas production from hydrolysis lignin: insight into lignin structural changes
}

Daniel Girma Mulat', Janka Dibdiakova² and Svein Jarle Horn ${ }^{*}$ (i)

\begin{abstract}
Background: The emerging cellulosic bioethanol industry will generate huge amounts of lignin-rich residues that may be converted into biogas by anaerobic digestion (AD) to increase the output of energy carriers from the biorefinery plants. The carbohydrates fraction of lignocellulosic biomass is degradable, whereas the lignin fraction is generally considered difficult to degrade during AD. The objective of this study was to investigate the feasibility of biogas production by AD from hydrolysis lignin (HL), prepared by steam explosion (SE) and enzymatic saccharification of birch. A novel nylon bag technique together with two-dimensional nuclear magnetic resonance spectroscopy, pyrolysis-gas chromatography-mass spectrometry (Py-GC/MS), and Fourier transform infrared (FTIR) spectroscopy was used to identify recalcitrant and degradable structures in the lignin during AD.
\end{abstract}

Results: The HL had a lignin content of $80 \%$ which included pseudo-lignin and condensed-lignin structures resulting from the SE pretreatment. The obtained methane yield from HL was almost twofold higher than the theoretical methane from the carbohydrate fraction alone, indicating that part of the lignin was converted to methane. Characterization of the undegradable material after AD revealed a substantial loss of signals characteristic for carbohydrates and lignin-carbohydrate complexes (LCC), indicating conversion of these chemical components to methane during AD. The $\beta-O-4^{\prime}$ linkage and resinol were not modified as such in AD, but major change was seen for the S/G ratio from 5.8 to 2.6 , phenylcoumaran from 4.9 to $1.0 \%$, and pseudo-lignin and condensed-lignin were clearly degraded. Scanning electron microscopy and simultaneous thermal analysis measurements demonstrated changes in morphology and thermal properties following SE pretreatment and AD. Our results showed that carbohydrate, LCC, pseudo-lignin, and condensed-lignin degradation had contributed to methane production. The energy yield for the combined ethanol production and biogas production was $8.1 \mathrm{MJ}$ fuel per $\mathrm{kg}$ DM of substrate $(4.9 \mathrm{MJ} / \mathrm{kg}$ from ethanol and $3.2 \mathrm{MJ} / \mathrm{kg}$ from methane).

Conclusion: This study shows the benefit of using a novel bag technique together with advanced analytical techniques to investigate the degradation mechanisms of lignin during $A D$, and also points to a possible application of $\mathrm{HL}$ produced in cellulosic bioethanol plants.

Keywords: Anaerobic digestion, Biogas, Hydrolysis lignin, Pseudo-lignin, Condensed lignin, Birch, Steam explosion, Biorefinery, Lignocellulosic biomass, NMR

\footnotetext{
*Correspondence: svein.horn@nmbu.no

${ }^{1}$ Faculty of Chemistry, Biotechnology and Food Science, Norwegian

University of Life Sciences, P.O. Box 5003, 1432 Ås, Norway

Full list of author information is available at the end of the article
} 


\section{Background}

In conventional first generation biorefineries based on starch and sucrose, the remaining fiber fraction is often burned to generate process heat. A similar trend is seen for the emerging second-generation cellulosic bioethanol plants, where the hydrolysis lignin (HL) is also burned to generate process heat. If the cellulosic bioethanol industry succeeds, the amount of HL produced will be very large as lignin is one of the main components of lignocellulosic biomass. For instance, the intended development of 79 billion liters of second-generation biofuels annually by 2022 in the USA would generate about 62 million tons of lignin [1], by far exceeding the current world market for lignin used in specialty products [2]. Since all these lignins are not needed for process heat, considerable efforts are underway for generating chemicals and other forms of energy from HL residues [3]. The production of highquality oil fraction from birch HL has been reported using intermediate pyrolysis and low-cost ZSM-5 catalyst downstream process [4]. Another possible pathway is anaerobic digestion (AD) of HL into biogas, which could increase the output of fuels and improve the economic profitability of such biorefineries.

Lignocellulosic biomass consists of three major structural biopolymers, namely, cellulose, hemicelluloses, and lignin. The cellulose microfibrils are locked in a matrix of intertwined hemicelluloses and lignin called lignincarbohydrate complex (LCC). Among the three lignocellulosic components, lignin is considered as the most recalcitrant to biological deconstruction due to its irregular, complex, and highly heterogeneous aromatic structure $[3,5]$.

Pretreatment is usually employed prior to biological processing for reducing biomass recalcitrance, mainly by increasing the accessibility of cellulose to enzymatic and microbial degradation. Various pretreatment methods have been applied for enhancing the digestibility of lignocellulosic biomass, including physical, chemical, biological, or combinations of these techniques [6-8]. Depending on the type of pretreatment, several characteristics of biomass are altered including biomass composition, lignin/carbohydrate structure, crystallinity, cellulose degree of polymerization, and accessibility (surface area, pore size, and pore volume) [5]. Steam explosion (SE) is considered as one of the most efficient pretreatment technologies and is one of few pretreatment techniques employed at industrial scale [9]. During SE pretreatment in a boiler, the biomass is exposed to high-pressure steam followed by a rapid decompression step, which disrupts the internal structure of lignocellulose. After SE pretreatment, enzymatic accessibility to the biomass is enhanced mainly due to opening of lignocellulosic fiber structure, solubilization of hemicelluloses, and redistribution of lignin [7].

Anaerobic digestion (AD) is a well-established technology for waste management and production of renewable energy in which organic material is converted to biogas. The conversion of complex organic compounds to biogas is possible due to the cooperation of several groups of microorganisms involved in hydrolysis, acidogenesis, acetogenesis, and methanogenesis steps [10]. Biogas consists mainly of methane (50-75\%) and carbon dioxide, their relative amounts depending on the type of feedstocks and operating conditions [11]. Upgraded biogas having higher methane content can be used as a substitute of natural gas for combined heat and electricity generation, as a vehicle fuel, and can be stored in a natural gas grid for later use $[11,12]$. The carbohydrate fraction of lignocellulosic biomass is degradable in AD, whereas the lignin fraction is generally considered difficult to degrade. Typically, the digestate collected from biogas digesters is rich in lignin due to the degradation of the other components [13]. However, AD of lignin has been observed in various natural environments [14-21], but studies on the fate of lignin degradation in engineered biogas systems are very limited. With a better understanding of the degradable and recalcitrant fractions of lignin during $\mathrm{AD}$, potential applications beyond combustion could be developed.

In this study, biogas production from HL was investigated in $\mathrm{AD}$. The chemical structure, morphology, and thermal properties of $\mathrm{HL}$ and the remaining undigested material after $\mathrm{AD}$ were characterized using a combination of advanced analytical techniques, including twodimensional nuclear magnetic resonance (2D-NMR) spectroscopy, pyrolysis-gas chromatography-mass spectrometry (Py-GC/MS), Fourier transform infrared (FTIR) spectroscopy, scanning electron microscopy (SEM), and simultaneous thermal analysis (STA). To our knowledge, this is the first study to employ comprehensive advanced analytical techniques for showing the degradation of lignin and the changes in lignin structures during AD.

\section{Methods}

\section{Inoculum and anaerobic medium}

The microbial inoculum used in this experiment was collected from a full-scale continuously stirred tank reactor (CSTR) (Biowaz, Tomb, Norway) running with food waste and cow manure at mesophilic temperature $\left(\sim 37^{\circ} \mathrm{C}\right)$. Dry matter $(\mathrm{DM})$ content of the inoculum was $4.5 \%$, the volatile solid (VS) content was $2.9 \%$, and the $\mathrm{pH}$ was 7.8 . This inoculum was pre-incubated anaerobically at $37^{\circ} \mathrm{C}$ for 10 days to reduce endogenous biogas production. Anaerobic medium was prepared from a mixture of 
buffer solution, trace elements, and vitamins according to Angelidaki et al. [22].

\section{Raw material}

Birch (Betula pubescens) wood chips originated from a tree harvested in 2009 in Norway $\left(60.7^{\circ}\right.$ North, $10.4^{\circ}$ East). The birch tree trunk was debarked and chipped to produce $20-30 \mathrm{~mm}$ chip fractions. These fractions were dried at room temperature and subsequently milled to pass a sieve of $6 \mathrm{~mm}$ (SM 2000, Retsch, Haan, Germany) and stored at room temperature and dry conditions. The DM and VS content of the dried birch was 94.9 and $94.8 \%$, respectively.

\section{Steam explosion (SE) pretreatment}

SE pretreatment was conducted using a steam explosion unit designed by Cambi AS (Asker, Norway) situated at Norwegian University of Life Science. In a previous study [23], the optimal steam explosion conditions of birch for biogas production were found to be pretreatment at $210{ }^{\circ} \mathrm{C}$ and $10 \mathrm{~min}$ residence time. Therefore, we used the same pretreatment conditions in this study. The non-washed steam-exploded material was stored in plastic bags at $4{ }^{\circ} \mathrm{C}$ until the start of the biogas experiment. The DM and VS content of the steam-exploded birch was 35.0 and $34.9 \%$, respectively.

\section{Preparation of hydrolysis lignin (HL)}

The pretreated birch was subjected to enzymatic hydrolysis using Cellic ${ }^{\circledR}$ CTec2 (Novozymes, Bagsvaerd, Denmark; the protein content of the enzymatic preparation was $63.9 \mathrm{mg} / \mathrm{ml}$ ). The material was added to screwcapped centrifuge tubes at a DM concentration of $10 \%$ and preheated at $50{ }^{\circ} \mathrm{C}$ before adding the enzyme. An enzyme loading of $5 \mathrm{mg} / \mathrm{g} \mathrm{DM}$ of substrate was used, $\mathrm{pH}$ was adjusted to $\mathrm{pH} 5.0$ by $50 \mathrm{mM}$ acetate buffer, and the incubation was carried out at $130 \mathrm{rpm}$ and $50{ }^{\circ} \mathrm{C}$ for $72 \mathrm{~h}$ to obtain a residue rich in lignin. The enzymatic reaction was stopped by heat deactivation at $100{ }^{\circ} \mathrm{C}$ for $10 \mathrm{~min}$. Following deactivation, the sample was centrifuged at $10,000 \times g$ for $4 \mathrm{~min}$, whereby the supernatant was filtered through $0.2 \mu \mathrm{m}$ and stored at $-20^{\circ} \mathrm{C}$ for later sugar analysis, whereas the solid HL was washed twice with deionized water and drying at $50{ }^{\circ} \mathrm{C}$. The $\mathrm{DM}$ and VS content of the wet HL birch was 34.7 and $34.3 \%$, respectively. The DM and VS content of the dried HL birch was 93.7 and $91.6 \%$, respectively.

\section{Batch experiment to test biogas potential}

The biogas production of untreated, steam-exploded, and HL birch was studied in $500 \mathrm{ml}$ batch bottles. In addition, control batch bottles were prepared using inoculum alone to correct for the endogenous biogas production.
All the bottles received equal amount of inoculum and anaerobic medium. The inoculum-to-substrate ratio was 2:1 (based on VS basis) as suggested by Holliger et al. [24]. The substrates were added individually into the batch bottles, while the control bottles received water instead of substrate. The bottles were flushed with nitrogen gas for $5 \mathrm{~min}$ and sealed with septum and aluminum caps to maintain anaerobic conditions. All the experiments were conducted in triplicate inside a shaker (Multitron Standard, Infors HT, Switzerland) at mesophilic condition $\left(37^{\circ} \mathrm{C}, 90 \mathrm{rpm}\right)$. The biogas experiment run for 39 days and terminated when the daily biogas rate on 3 consecutive days was below $1 \%$ [24].

\section{Lignin degradation in $A D$ using nylon bags}

The degradation of HL in AD was investigated by enclosing the substrates in nylon bags. The nylon bag had a pore size of $25 \mu \mathrm{m}$ ( $9 \mathrm{~cm}$ wide $\times 12 \mathrm{~cm}$ long, made from permeable nylon tissue, F57, ANKOM Technology, USA) which allowed the contact between the anaerobic microbes and the substrate enclosed by the bag. This technique is commonly employed for evaluating the in vivo digestibility of animal feed in the rumen of fistulated animals $[25,26]$.

The nylon bag was first weighed and the desired amount of substrate (about $1.0 \mathrm{~g} \mathrm{DM}$ ) was transferred into the bag and heat-sealed afterwards. The sealed bags were added into the serum bottles containing inoculum and anaerobic medium. The headspace of the bottles was flushed with nitrogen gas for 5 min to maintain anaerobic conditions and then sealed with septum and aluminum caps. All the experiments were conducted in triplicate in shaker at $37^{\circ} \mathrm{C}$ as described above. After 39 days of AD, all nylon bags were collected and washed under running water and dried in an oven at $50{ }^{\circ} \mathrm{C}$. The dried bag was opened to collect the undigested substrate for further characterization of the material with advanced analytical techniques such as NMR, FTIR, Py-GC/MS, STA, and SEM as described below. The nylon bags from triplicate bottles were collected and the undegradable materials remaining inside the nylon bags were pooled together.

\section{${ }^{1} \mathrm{H}-{ }^{13} \mathrm{C}$ heteronuclear single quantum coherence (HSQC) nuclear magnetic resonance (NMR) analysis}

The 2D HSQC NMR spectra were recorded on a Bruker AVIII $400 \mathrm{MHz}$ spectrometer at $25{ }^{\circ} \mathrm{C}$. About $50 \mathrm{mg}$ of sample was dissolved in $0.75 \mathrm{ml}$ of DMSO- $d_{6}(99.8 \%$ D). Bruker's "hsqcetgpsi2" pulse program with $5000 \mathrm{~Hz}$ (from 10 to $0 \mathrm{ppm}$ ) and $20,843 \mathrm{~Hz}$ (165 to $0 \mathrm{ppm}$ ) for the ${ }^{1} \mathrm{H}$ - and ${ }^{13} \mathrm{C}$-dimensions, respectively, was used. The number of collected complex points was $2 \mathrm{~K}$ for the ${ }^{1} \mathrm{H}$ dimension with a recycle delay of $5 \mathrm{~s}$. The number of transients was 120, and 256 time increments were always 
recorded in the ${ }^{13} \mathrm{C}$ dimension. ${ }^{1} \mathrm{~J}_{\mathrm{C}-\mathrm{H}}$ used was $145 \mathrm{~Hz}$. Processing used typical matched Gaussian apodization in the ${ }^{1} \mathrm{H}$ dimension and squared cosine-bell apodization in the ${ }^{13} \mathrm{C}$ dimension. Prior to Fourier transformation, the data matrixes were zero filled up to 1024 points in the ${ }^{13} \mathrm{C}$ dimension. The central solvent peak was used as an internal reference $\left(\delta_{\mathrm{C}} 39.5 ; \delta_{\mathrm{H}} 2.49\right)$. HSQC correlation peaks were assigned by comparison with the literatures [27-29]. A semi-quantitative analysis [27] of the volume integrals (uncorrected) of the HSQC correlation peaks was performed using standard Bruker Topspin 2.1 NMR software. In the aliphatic oxygenated region, the relative abundances of side chains involved in the various interunit linkages were estimated from the $\mathrm{C}_{\alpha}-\mathrm{H}_{\alpha}$ correlations to avoid possible interference from homonuclear ${ }^{1} \mathrm{H}-{ }^{1} \mathrm{H}$ couplings. In the aromatic/unsaturated region, $\mathrm{H}_{2,6}$ and $\mathrm{S}_{2,6}$ correlations from $p$-hydroxyphenyl $(\mathrm{H})$ and syringyl (S) lignin units, respectively, and $\mathrm{G}_{2}$ correlation from guaiacyl $(G)$ were used to estimate their relative abundances [27]. For semi-quantitative calculation, part of the aromatic region is defined as internal standard and the amount of linkages and units are expressed as a number per 100 aromatic units $(\mathrm{H}+\mathrm{G}+\mathrm{S})$. Half of the volume integral of $\mathrm{H}_{2,6}$ and $\mathrm{S}_{2,6}$ correlation peak was used as the area of the $\mathrm{H}_{2,6}$ and $\mathrm{S}_{2,6}$ correlation peaks corresponds to twice the amount of $\mathrm{H}$ and $\mathrm{S}$ units, respectively (i.e., $\mathrm{H}_{2,6} / \mathrm{S}_{2,6}$ peak contains $\mathrm{H}_{2} / \mathrm{S}_{2}$ and $\mathrm{H}_{6} / \mathrm{S}_{6}$ correlations). The integral value obtained for the $\mathrm{H}_{2,6} / 2+\mathrm{S}_{2,6} / 2+\mathrm{G}_{2}$ is then set to 100Ar.

\section{Fourier transform infrared (FTIR) spectroscopy analysis}

The FTIR spectra were obtained on a Nicolet iS50 FTIR spectrophotometer (Thermo Scientific, USA). Each sample was deposited uniformly on the surface of the glass disc and the FTIR spectra was acquired against preestablished background by averaging 64 scans from 4000 to $650 \mathrm{~cm}^{-1}$ at $4 \mathrm{~cm}^{-1}$ resolution.

\section{Pyrolysis-gas chromatography-mass spectrometry (Py- GC/MS) analysis}

Py-GC/MS measurements were performed with a filament pulse pyrolyzer (Pyrola2000, PyrolAB, Sweden), which was connected to a GC/MS instrument (7000C Triple Quadrupole GC/MS System; Agilent Technologies, Inc., Bellevue, WA, USA). About $100 \mu \mathrm{g}$ of the sample was placed directly on the Pt filament, which contained a small cavity. Pyrolysis chamber maintained at $175{ }^{\circ} \mathrm{C}$ was purged with Helium $18 \mathrm{ml} / \mathrm{min}$ to lead the pyrolysis products into the gas chromatography injector, which contained split liner (Restek, $3.4 \mathrm{~mm} \times 5.0 \mathrm{~mm} \times 54 \mathrm{~mm}$ ). The instrument (Pyrola 2000) is capable of fast pyrolysis with a heating rate of $175^{\circ} \mathrm{C} / \mathrm{ms}$. Temperature rise time to the final pyrolysis temperature $600{ }^{\circ} \mathrm{C}$ was set to $8 \mathrm{~ms}$ and total pyrolysis time was $2 \mathrm{~s}$. Pyrolysis products were separated using a capillary column (TraceGOLD TG1701MS, $60 \mathrm{~m} \times 0.25 \mathrm{~mm}$ i.d, $0.25 \mu \mathrm{m}$ film thickness; ThermoFisher Scientific), using the following temperature program: $4 \mathrm{~min}$ at $50{ }^{\circ} \mathrm{C}, 5^{\circ} \mathrm{C} / \mathrm{min}$ to $130{ }^{\circ} \mathrm{C}, 4 \mathrm{~min}$ hold at $130{ }^{\circ} \mathrm{C}, 2{ }^{\circ} \mathrm{C} / \mathrm{min}$ to $170{ }^{\circ} \mathrm{C}, 4 \mathrm{~min}$ hold at $170{ }^{\circ} \mathrm{C}$, $5{ }^{\circ} \mathrm{C} / \mathrm{min}$ to $270^{\circ} \mathrm{C}$, and $4 \mathrm{~min}$ hold at $270{ }^{\circ} \mathrm{C}$. Helium was used as a carrier gas, using constant flow rate of $1.0 \mathrm{ml} /$ $\mathrm{min}$. The pyrolysis interface, injector, detector, and transfer line temperatures were kept at 201, 250, 250, and $250{ }^{\circ} \mathrm{C}$, respectively. The MS was operated in EI mode with $70 \mathrm{eV}$ electron and with full scan mode between $\mathrm{m} / \mathrm{z}$ 40 and 720 . Average of at least two measurements was calculated and the peak areas of the pyrolysis products were normalized to $100 \%$. The pyrolysis products formed were identified using standard samples, data from the literature [30-33], and commercial NIST 11 MS library.

\section{Simultaneous thermal analysis (STA)}

STA was used to investigate the thermal behavior and chemical composition of all investigated samples. The experiments were set up on a Simultaneous Thermal Analyzer apparatus (STA, Netzsch 449 F1 Jupiter) with the enthalpy determination accuracy of $3 \%$. About $6 \mathrm{mg}$ of each birch powder and reference material were placed into separate $\mathrm{Al}_{2} \mathrm{O}_{3}$ crucibles $(0.3 \mathrm{ml}$ volume) without lid and were put into the silicon carbide furnace sample holder while heating at a constant heating rate of $10 \mathrm{~K} /$ min from 40 to $600{ }^{\circ} \mathrm{C}$. The experiment was performed under an oxidizing atmosphere $\left(\mathrm{N}_{2} / \mathrm{O}_{2} 80: 20 \mathrm{vol}\right.$ \%) [34, 35]. The experiment was conducted at atmospheric pressure and using a volume flow rate of $20 \mathrm{ml} / \mathrm{min}$. A synthetic air, used as purged and protective gas, was allowed to flow into the apparatus prior to each run, where the volume flow rate was maintained constant at $20 \mathrm{ml} / \mathrm{min}$ and atmospheric pressure. The temperature difference of samples was measured at heating rate of $10 \mathrm{~K} / \mathrm{min}$. After each single sample measurement, the furnace was cooled down to ambient temperature to get ready for the next run. The experimental measurements of all samples were repeated three times. Thermogravimetric (TG) and Gram Schmidt (GS) curves of samples were corrected by the baseline obtained from runs with empty crucibles.

\section{Acid-insoluble lignin and carbohydrate analysis}

Samples for carbohydrate and acid-insoluble lignin content analysis were prepared using a standard NREL two-stage acid hydrolysis protocol [36]. Acid hydrolysis generates soluble sugars and acid-insoluble lignin residues, where the later was oven-dried and weighed to obtain the acid-insoluble lignin (Klason lignin) content. The soluble sugars were analyzed for carbohydrate constituents by high-performance anion-exchange 
chromatography with pulsed amperometric detection (HPAEC-PAD) using Dionex ICS-3000 (Dionex Corp., USA).

\section{Biogas composition and calculation}

The biogas production was periodically monitored by measuring the gas pressure in the headspace of the batch bottles using a digital pressure transducer (GMH 3161, Greisinger Electronic, Germany). After recording the pressure in the batch bottles, the overpressure was released by penetrating the septum with a needle. To avoid excessive dissolution of $\mathrm{CO}_{2}$ with possible effects on $\mathrm{pH}$, the overpressure was always kept below $200 \mathrm{kPa}$ [24]. The biogas composition $\left(\mathrm{CH}_{4}\right.$ and $\left.\mathrm{CO}_{2}\right)$ was analyzed by gas chromatography (GC) using a gas chromatograph (3000 Micro GC, Agilent Technologies, USA) equipped with a thermal conductivity detector (TCD). Using the measured overpressure, headspace volume of the bottles and measurements of methane concentrations as input, the ideal gas law was applied for calculating methane production. The methane production was reported at standard temperature and pressure $\left(0{ }^{\circ} \mathrm{C}\right.$ and $1 \mathrm{~atm}$.) after correcting the background methane production from inoculum alone (control). The average results of the biological triplicates are presented with standard deviations.

\section{Other analytical methods}

Dry matter (DM) and volatile solids (VS) of substrates were analyzed according to the standard methods [37].

\section{Scanning electron microscopy (SEM) analysis}

After mounting dry samples on aluminum specimen stubs and sputter coating with gold, SEM images of birch samples were acquired on a Zeiss EVO 50VP (Cambridge, UK) SEM at $15 \mathrm{kV}$ beam accelerating voltage and various resolving powers. Several pictures were taken at different magnifications $(200 \times$ to $15,000 \times$ magnification) for each sample surface. First, low magnification was applied to obtain an overview of the sample surface's topographical features and morphology, and then, pictures were taken at higher magnification, focusing on typical surface features.

\section{Results and discussion}

Substrates characteristics

The DM, VS, and $\mathrm{pH}$ of the untreated, pretreated and HL birch samples differed considerably. The DM content decreased from $94.8 \%$ in untreated birch to $35.0 \%$ in steam-exploded birch as steam is added to the biomass during pretreatment. The washed and centrifuged HL had a DM content of $34.7 \%$. In comparison with the VS content of $99.8 \%$ (DM basis) for untreated and pretreated birch, the VS of HL birch was slightly lower (98.7\%), indicating an enrichment of ashes in the HL. The $\mathrm{pH}$ of steam-exploded birch was 3.0, which was lower than the pH 5.0 of HL birch. The low pH can be explained by the release of organic acids from the degradation of hemicelluloses during SE pretreatment [38]. The elevated $\mathrm{pH}$ of $\mathrm{HL}$ is the result of $\mathrm{pH}$ adjustment to 5.0 before the enzymatic hydrolysis. The $\mathrm{pH}$ of the HL residue and steamexploded material was corrected to $7-8$ prior to the biogas experiments.

The content of cellulose, hemicelluloses, and Klason lignin in the three birch samples is summarized in Table 1. The proportion of cellulose and Klason lignin in the steam-exploded birch increased, while the amount of hemicelluloses (mainly xylan) was reduced. Such large reductions in the content of hemicelluloses have been reported in a previous study of birch pretreated with SE [23]. The employed high temperature and acidic conditions (released organic acids) during SE can catalyze the hydrolysis of hemicelluloses and further degradation into lower molecular weight (LMW) compounds such as furfural. These LMW compounds may undergo polymerization reactions, forming a lignin-like material termed "pseudo-lignin" [39]. Thus, formation of pseudolignin was probably the main reason for the increase in the lignin fraction after pretreatment, although loss of volatiles during SE formed from hemicellulose would

Table 1 Chemical composition of different birch samples

\begin{tabular}{|c|c|c|c|c|c|c|}
\hline \multirow[t]{2}{*}{ Birch } & \multicolumn{6}{|c|}{ Composition (\%) } \\
\hline & Glucan $^{b}$ & Arabinan & Galactan & Xylan & Mannan & Klason lignin \\
\hline Untreated & $36.5 \pm 2.04$ & $1.1 \pm 0.02$ & $1.4 \pm 0.04$ & $16.5 \pm 0.42$ & $2.8 \pm 0.12$ & $29.2 \pm 1.12$ \\
\hline Steam-exploded ${ }^{a}$ & $43.2 \pm 2.06$ & $0.3 \pm 0.01$ & $0.9 \pm 0.04$ & $9.9 \pm 0.08$ & $1.7 \pm 0.02$ & $40.3 \pm 1.02$ \\
\hline $\mathrm{HL}$ & $9.7 \pm 1.01$ & & $0.1 \pm 0.01$ & $1 \pm 0.02$ & $0.6 \pm 0.01$ & $79.8 \pm 3.27$ \\
\hline
\end{tabular}

The amounts of all components are expressed as a percentage of dry matter. The amount of carbohydrates was calculated using the mass of anhydrous sugar

a The SE material was not washed and represents the whole slurry obtained after the pretreatment

b It should be noted that while almost all of the glucan originate from cellulose, hemicelluloses also contain some glucose that will contribute to the glucan fraction 
also contribute to an increase in the lignin and cellulose fraction. It should be noted that the SE material was not washed and represents the whole slurry obtained after the pretreatment. Pseudo-lignin has been shown to be detrimental to cellulosic enzymatic hydrolysis of cellulose [40], but its fate in AD is unknown. During enzymatic saccharification, pseudo-lignin deposits on polysaccharides could lead to non-productive binding of enzymes and acts as a barrier to accessing cellulose and thereby reducing cellulose breakdown [40]. After enzymatic hydrolysis of the pretreated material, the carbohydrate fraction of HL birch was substantially reduced to $10 \%$ and the Klason lignin increased accordingly to $80 \%$. The obtained sugar yield after pretreatment was $90 \%$ of the theoretical sugar expected. The remaining 10\% carbohydrates and part of the lignin fraction in the HL birch could be potential substrates for methane production.

\section{Biogas potential of hydrolysis lignin}

Figure 1 shows the cumulative methane yield of untreated, pretreated, and HL birch monitored for 39 days. The initial rate of methane production of pretreated and HL birch was higher than untreated birch, indicating an increased accessibility of the birch material to anaerobic bacteria after SE pretreatment. While the steam-exploded birch reached maximum methane yield after 16 days, the untreated material needed 39 days to reach similar yields. In this study, the main effect of SE pretreatment is on the rate of methane production, not on the final yield. Previous studies have shown that SE can increase the initial methane production rate, but that the increase in methane yield depends primarily on the type of substrate and severity factor (function

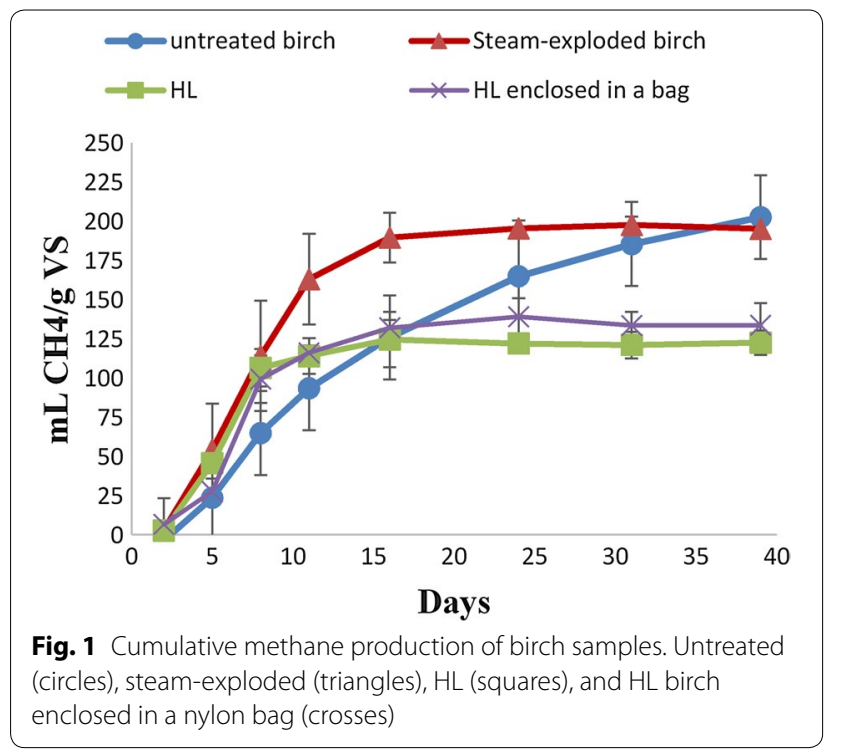

of temperature and residence time). The methane yield increased from $291 \mathrm{ml} / \mathrm{g}$ VS in untreated rape straw to $257 \mathrm{ml} / \mathrm{g}$ VS in SE pretreated straw at higher severity factor $\left(230^{\circ} \mathrm{C}, 10 \mathrm{~min}\right)$ [41]. The initial methane production rate also increased with an increase in the severity of pretreatment (i.e., with increasing time and temperature). In another study of a sugarcane bagasse subjected to SE pretreatment, the methane production rate was improved substantially and methane yield was increased by 1.3 times than the yield from untreated bagasse [42]. In another batch biogas experiment with wheat straw steam-exploded at three different conditions (180, 200, and $220{ }^{\circ} \mathrm{C}$ for the same residence time of $15 \mathrm{~min}$ ), the methane yield significantly increased for only the pretreated material at $180^{\circ} \mathrm{C}$ [43].

Figure 1 shows that the methane potential of HL residues originated after enzymatic removal of the carbohydrates. The final methane yield of HL birch was $125 \mathrm{ml}$ $\mathrm{CH}_{4} / \mathrm{g}$ VS, reached after 16 days of incubation. Considering the carbohydrate composition of HL birch (Table 1) and a theoretical methane yield of $415 \mathrm{ml} / \mathrm{g}$ DM of carbohydrates, about $47 \mathrm{ml}$ of methane could be expected to be produced from the carbohydrate fraction. The observed methane yield of $125 \mathrm{ml} \mathrm{CH}_{4} / \mathrm{g}$ VS from HL birch must mean that part of the lignin fraction of $\mathrm{HL}$ also was converted into methane. There are few studies on biogas production of lignin-rich residues in a biorefinery setting. Batch biogas bottles fed with lignin-rich residues of hemp showed that the methane yield was similar to untreated hemp (i.e., $127 \mathrm{ml} \mathrm{CH}_{4} / \mathrm{g}$ VS) [44]. This lignin-rich material was a residue remaining after distillation of bioethanol from fermentation broth. The hemp was pretreated by $\mathrm{SE}\left(210^{\circ} \mathrm{C}\right.$ for $5 \mathrm{~min}$ after impregnation with $\left.2 \% \mathrm{SO}_{2}\right)$ to improve the bioethanol production during simultaneous saccharification and fermentation. It should be noted that residual bioethanol, the enzyme solutions, yeast, and yeast extract all contain carbon sources and can contribute to methane production [44]. In another study, alkalipretreated sugarcane bagasse was used for combined bioethanol and biogas production based on a high-solid fed-batch SSF (simultaneous saccharification and fermentation) process with delayed inoculation (DSSF) [45]. The lignin-rich residue after evaporation of the bioethanol gave a high methane yield of $307 \mathrm{ml} \mathrm{CH}_{4} / \mathrm{g} \mathrm{VS}$ compared to our study and others [44]. The high methane yield could be due to a high content of processing residues such as yeast and residual bioethanol.

The energy content of produced methane and theoretically produced ethanol was calculated (Fig. 2) to evaluate the energy recovery from only methane production (process no. 1), only ethanol production (process no. 2), and combined ethanol and methane production (process no. 2 and 3 ). In a combined ethanol and methane production, 


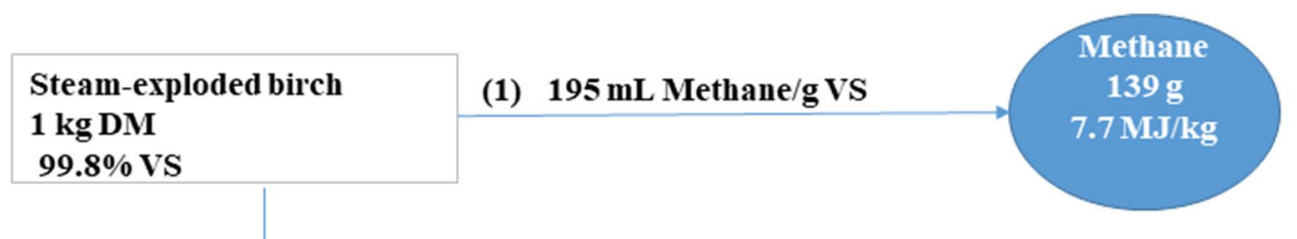

(2) $0.47 \mathrm{~g}$ Ethanol/g Glucose

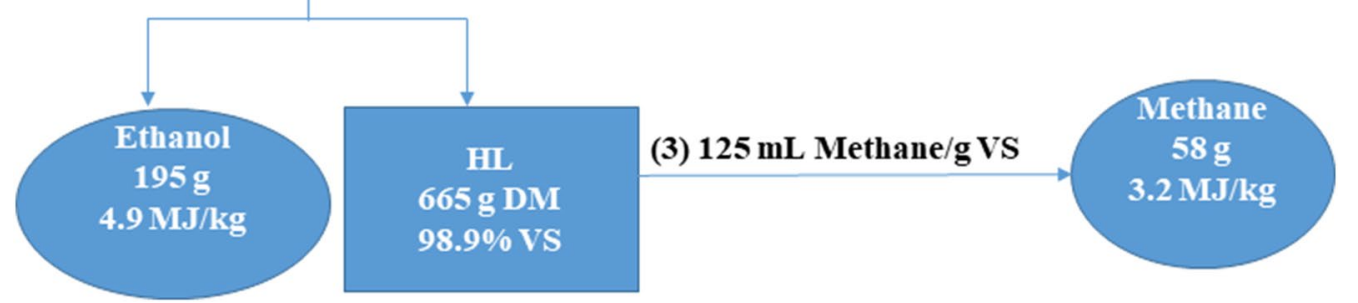

Fig. 2 Process scheme for methane and bioethanol production from birch. Methane production from steam-exploded birch (1), ethanol production from steam-exploded birch (2), and methane production from HL residue (3). The combined ethanol and methane production is represented by combination of (2) and (3)

ethanol is produced from the steam-exploded material and the methane from the HL residue. For calculations, 26.8 and $55.7 \mathrm{MJ} / \mathrm{kg}$ were used as the high heating values (HHV) of ethanol and methane, respectively. Our group previously used the same substrate and obtained a maximum ethanol yield of $0.47 \mathrm{~kg} / \mathrm{kg}$ of glucose for substrate loading of $10 \% \mathrm{w} / \mathrm{w}$ was used [46]. The combined ethanol and methane production gave an energy yield of $8.1 \mathrm{MJ}$ fuel per $\mathrm{kg}$ DM of substrate $(4.9 \mathrm{MJ} / \mathrm{kg}$ from ethanol and $3.2 \mathrm{MJ} / \mathrm{kg}$ from methane), which is higher than the yield from only methane production $(7.7 \mathrm{MJ} / \mathrm{kg})$ or only ethanol production $(4.9 \mathrm{MJ} / \mathrm{kg})$. For steam-exploded sugarcane bagasse, the combined process gave $7.1 \mathrm{MJ} / \mathrm{kg}$ of energy, whereas only $4.1 \mathrm{MJ} / \mathrm{kg}$ of energy was obtained from bioethanol production alone [42]. In another experiment with steam-exploded oat straw, $9.5 \mathrm{MJ} / \mathrm{kg}$ of energy was achieved for the combined process and $7.4 \mathrm{MJ} / \mathrm{kg}$ for methane alone [47]. Thus, utilization of lignin-rich residues after bioethanol production for production of biogas may clearly increase the output of energy carriers from lignocellulosic biomass.

\section{Nylon bag technique optimization}

The nylon bag technique was originally developed for evaluating the digestibility of animal feed [26], but its use in engineered biogas digesters is very limited. This technique is widely used for in vivo degradation studies, where animal feed enclosed in a bag is directly introduced into a rumen of a living animal through fistulas before finally removed and washed for subsequent chemical analysis [25, 26]. Given the similarity of rumen system and biogas digesters, we adopted this technique for evaluating degradation of HL in biogas digesters.

The main purpose of using of the nylon bag technique was to collect a clean material of the undigested substrate after $\mathrm{AD}$, which would be suitable for further chemical and structural analysis. It should be noted that the inoculum, which originated from a food waste and manure treating biogas plant, contained some fiber material that would contaminate the lignin-rich birch if it was not enclosed in a nylon bag. With the use of an appropriate pore size of the nylon bags, we retained the lignin substrate inside the bag and allowed contact between the substrate and microbes while avoiding contamination of the substrate with the fibers originating from the inoculum (see the discussion below). Since microbes can get in and out of the bags, the bags were washed with running water to remove the microbes prior to harvesting the undigested lignin.

AD of HL enclosed in a nylon bag gave very similar methane production rate and yield as the one without nylon bag (Fig. 1), showing that the nylon bag does not influence the $\mathrm{AD}$ process. Use of nylon bags may affect methane production in CSTRs operated for long periods, since the nylon bags could create a surface conducive for the establishment of microbial biofilms [48, 49]. This may affect the accessibility of the substrates to microorganisms, provide closer interspecies distance between bacterial and methanogens, and increase the retention time of the microbes in the reactor. Our results showed that the use of nylon bag did not influence AD process, which could be due to the short operating period in the batch experiments reducing microbial biofilm formation. 
A nylon bag with low porosity is needed to reduce substrate leak and contamination of the undigested substrate with fiber materials originating from inoculum, while at the same time permeable for the anaerobic microbes. Moreover, the amount of substrates enclosed in nylon bags should not be increased to the level that physically reduces the contact between microbes and substrate. The similarity of methane production of HL with and without nylon bag, together with the acquired high-quality chemical data of the undigested substrate (see the discussion in next section), confirmed that enclosing about $1.0 \mathrm{~g}$ DM of HL in the nylon bags $(9 \mathrm{~cm}$ wide $\times 12 \mathrm{~cm}$ long, a porosity of $25 \mu \mathrm{m}$ ) was an appropriate amount.

\section{Insight into lignin structural changes after pretreatment and $A D$ \\ NMR analysis}

The HSQC spectral regions of interest for untreated birch MWL, birch HL before and after AD as well as the structures of the main lignin units and lignin interunit linkages are shown in Figs. 3 and 4, respectively. The regions displayed include the aromatic structures of lignin (Fig. 3) and the aliphatic lignin-side chains (Fig. 4). The relative abundance of different inter-unit linkages per 100Ar, S units, G units, and S/G ratios is shown in Table 2. Detail assignments of correlation peaks are given in Additional file 1: Table S1. The HSQC NMR spectrum of MWL prepared from untreated birch, representing native lignin in birch [28] showed that birch is a typical hardwood (S/G-type lignin) with substantial amounts of $\mathrm{S}$ units, $\mathrm{G}$ units, lignin methoxyls and an $\mathrm{S} / \mathrm{G}$ ratio of 2.8 (Fig. 3 and Table 2). The lignin-side-chain correlations
(Fig. 4) for untreated birch MWL show that $\beta-O-4^{\prime}$ was the major lignin inter-unit linkage $(67 \%$, substructure $A)$, followed by resinol units (13\%, substructure B) and phenylcoumaran units $(2.6 \%$, substructure $C)$. Our results are comparable with a previous HSQC NMR study of birch reaching $2.0 \mathrm{~S} / \mathrm{G}, 69 \% \beta-\mathrm{O}-4^{\prime}, 17 \%$ resinol, and 3\% phenylcoumaran [50].

The change in lignin structure after SE pretreatment was investigated by comparing the HSQC spectra between untreated birch MWL and birch HL (Figs. 3, 4 , and Table 2). The $\beta-\mathrm{O}-4^{\prime}$ linkage was substantially reduced from $67 \%$ in untreated birch to $18 \%$ in $\mathrm{HL}$, showing the cleavage of this major lignin linkage by $\mathrm{SE}$ pretreatment. The correlation peak of $\mathrm{S}_{2,6}$ at $\delta \mathrm{C} / \delta \mathrm{H}$ $105 / 6.6 \mathrm{ppm}$ became broad due to overlap with other signal, which was not observed in untreated birch spectra. Therefore, the calculated S/G ratio increased from 2.8 in untreated birch to 5.8 in $\mathrm{HL}$ as the $\mathrm{C}-\mathrm{H}$ correlation of $\mathrm{S}_{2,6}$ at $\delta \mathrm{C} / \delta \mathrm{H} 105 / 6.6$ increased due to signal overlap. An additional $\mathrm{C}-\mathrm{H}$ correlation appeared at $\delta \mathrm{C} /$ $\delta \mathrm{H} 112.3 / 6.75 \mathrm{ppm}$ in $\mathrm{HL}$, which has not been reported previously. These new signals could be associated with the formation of pseudo-lignin in HL, as it has a ligninlike aromatic structure $[40,51]$. It could also be associated with modification of aromatic ring in native lignin, resulting in a formation of condensed-lignin [38, 52, 53]. A condensed-G-type lignin results from a new bond formed between the $G_{5}$ and/or $G_{6}$ positions of $G$ units and other lignin unit [53]. While the exact structures of condensed lignin formed in S units remained unknown. It is hypothesized that the condensed position in $\mathrm{S}$ units is probably located at $C_{\alpha}$ of the side chain, which forms a

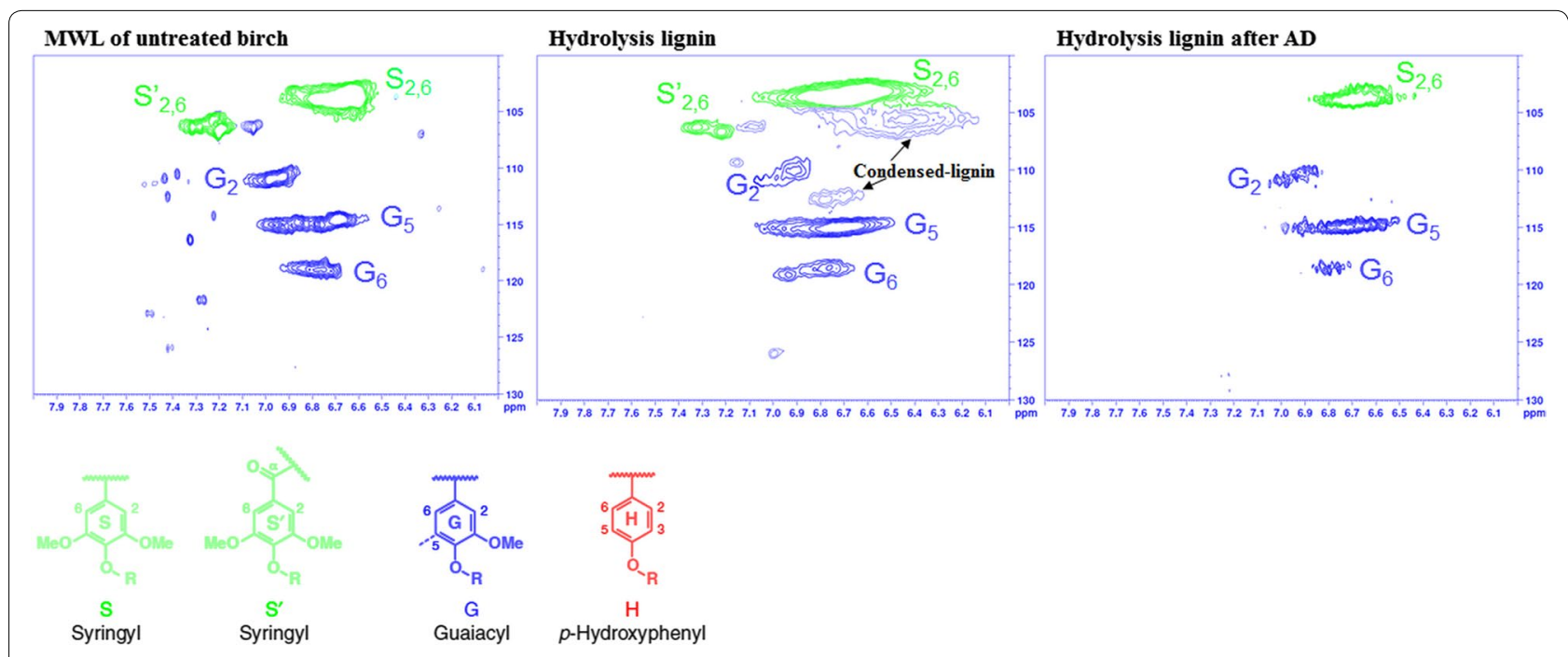

Fig. 3 The 2D HSQC NMR spectral regions of interest (aromatic region) for birch samples and the structures of main lignin units ( $S, G$, and $H)$. Numbers indicate carbon atoms in the aromatic ring. For well-resolved correlation peaks, contours are color coded to match their structures shown 


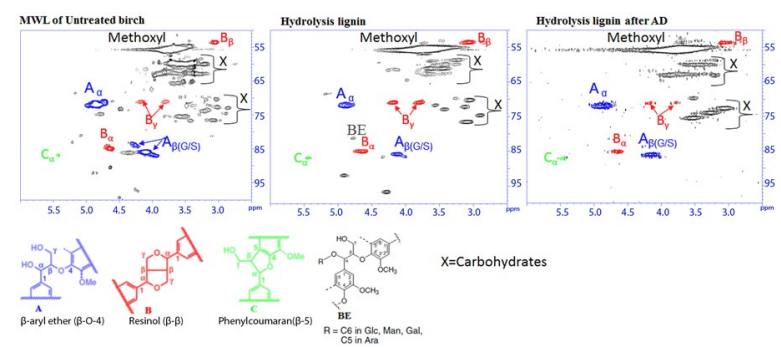

Fig. 4 The 2D HSQC NMR spectral regions of interest (aliphatic region) for birch samples and the structures of lignin inter-unit linkages. The letters found in the spectra refer to the substructures shown below the spectra. For well-resolved correlation peaks, contours are color coded to match their structures shown

new $\mathrm{C}-\mathrm{C}$ bond between an aromatic ring and a reactive carbonium ion, normally located at $\mathrm{C}_{\alpha}$ of the side chain [54]. Moreover, the decrease in $G_{6} / G_{5}$ ratio from 0.5 to 0.3 after SE pretreatment suggests that the formation of condensed lignin is higher at the $G_{6}$ position of $G$ units as reported previously [53]. $\mathrm{G}_{6}$ has higher potential to participate in condensation reactions, since it is para to the methoxy group. It should be noted that the HSQC signals are originated from the non-substituted $\mathrm{C}-\mathrm{H}$ bonded aromatic positions in condensed-lignin structures, whereas the new $\mathrm{C}-\mathrm{C}$-bonded aromatic positions do not produce cross correlations.

The changes in lignin structure after SE pretreatment also clearly shown by changes in other lignin-side changes. Notably, the signal intensity of phenylcoumaran increased after SE, which could be due to formation of new phenylcoumaran bond following the cleavage of $\beta-\mathrm{O}-4^{\prime}$ linkages as demonstrated by Heikkinen et al. [52]. The intensity of resinol signals was not significantly changed after SE pretreatment, indicating the resistance of this bond to modification by SE pretreatment. The presence of minor amount of benzyl ether (BE, 4\%) in birch HL and its absence in the untreated birch MWL could indicate limitations in the MWL method for isolating lignin containing the $\mathrm{BE}$ substructure. Our results are in agreement with a previous study [28], where cellulosic enzymatic hydrolysis and MWL lignin isolation methods were the best and worst, respectively, to study BE lignin-carbohydrate complex (LCC) linkages. Over all, the HSQC NMR results show the modification of lignin structure after SE, particularly the simultaneous cleavage of $\beta-\mathrm{O}-4^{\prime}$ aryl-ether linkages and re-condensation to form $\beta-5^{\prime}$ linkages and other condensed-lignin structures.

On day 39, the nylon bags were removed from the biogas digesters running with HL to characterize the chemical structure, morphology, and thermal properties of the remaining solid material by NMR, Py-GC/MS, FTIR, SEM, and STA methods. The HSQC spectra of the original HL substrate and the remaining $\mathrm{HL}$ after $\mathrm{AD}$ are shown in Figs. 3 and 4. In comparison with the original $\mathrm{HL}$ substrate, the $\mathrm{S} / \mathrm{G}$ ratio of the material after $\mathrm{AD}$ was reduced to 2.6 (Table 2) and the $\mathrm{S}_{2,6}$ correlation at $\delta \mathrm{C} / \delta \mathrm{H}$ $105 / 6.6 \mathrm{ppm}$ became as narrow as the untreated birch MWL. These results in conjunction with the absence of correlation at $\delta \mathrm{C} / \delta \mathrm{H} 112.3 / 6.75 \mathrm{ppm}$ indicate the degradation of pseudo-lignin and/or condensed-lignin during $\mathrm{AD}$. The proportion of phenylcoumaran and $\mathrm{BE}$ was reduced during $\mathrm{AD}$ from 5 to $1 \%$, and from $4 \%$ to below detection limit, respectively, whereas the proportion of $\beta-\mathrm{O}-4^{\prime}$ and resinol did not change. Degradation of $\mathrm{BE}$ linkage of lignin in AD by ruminal microbes has been reported previously [55], but the degradation of phenylcoumaran linkage of lignin has not been reported. The cleavage of LCC like BE may be due to the solubilization of the carbohydrate component. As expected, the HSQC NMR results show that polysaccharide signals were diminished substantially after AD (Fig. 4).

\section{FTIR analysis}

FTIR spectroscopy analysis was used to further investigate changes in the chemical structure of birch samples caused by SE and AD (Additional file 1: Figure S1). All birch samples exhibited the characteristic bands of cellulose including $\mathrm{C}-\mathrm{H}$-stretching vibration in aliphatic $\left(2922 \mathrm{~cm}^{-1}\right)$, the $\mathrm{C}-\mathrm{O}-\mathrm{C}$ symmetric and antisymmetric stretching (1370 and $1162 \mathrm{~cm}^{-1}$, respectively) and $\mathrm{C}-\mathrm{O}$ valence vibrations $\left(1015-1060 \mathrm{~cm}^{-1}\right)$ as well as vibration of the aromatic ring $\left(1600-1616,1515 \mathrm{~cm}^{-1}\right), \mathrm{C}-\mathrm{H}$ bending vibration in methyl groups $\left(1460-1470 \mathrm{~cm}^{-1}\right)$

Table 2 Abundance of major lignin inter-unit linkages and S/G for birch samples

\begin{tabular}{|c|c|c|c|c|c|c|c|}
\hline \multirow[t]{2}{*}{ Materials } & \multicolumn{4}{|c|}{ Amounts per 100Ar (\%) } & \multicolumn{2}{|c|}{ Weight (\%) } & \multirow[t]{2}{*}{$\mathrm{S} / \mathrm{G}$} \\
\hline & $\beta-0-4^{\prime}$ & $\beta-\beta$ & $\beta-5$ & $\mathrm{BE}$ & $S$ & G & \\
\hline MWL of untreated birch & 66.9 & 13.3 & 2.6 & $\mathrm{BD}^{\mathrm{a}}$ & 74.0 & 26.0 & 2.8 \\
\hline HL birch & 18.6 & 11.0 & 4.9 & 3.9 & 85.0 & 15.0 & 5.8 \\
\hline$H L$ birch after $A D$ & 23.5 & 9.6 & 1.0 & $\mathrm{BD}$ & 72.0 & 28.0 & 2.6 \\
\hline
\end{tabular}

a $\mathrm{BD}$ means below detection limit 
and a broad band between 3000 and $3600 \mathrm{~cm}^{-1}$ representing -OH-stretching vibrations [56-58]. The band at $1716-1733 \mathrm{~cm}^{-1}$ in untreated (Additional file 1: Figure S1A) and pretreated (Additional file 1: Figure S1B) samples is typical $\mathrm{C}=\mathrm{O}$ stretching in hemicelluloses [59] and/or pseudo-lignin [40,51]. Despite the loss of some of the hemicelluloses after pretreatment (Table 1), a higher intensity of the band at $1716-1733 \mathrm{~cm}^{-1}$ was seen for the pretreated sample suggesting the formation of pseudolignin after SE pretreatment. The higher intensity of a signal at $1615-1600 \mathrm{~cm}^{-1}$ after pretreatment, representing $\mathrm{C}=\mathrm{O}$ conjugated to aromatic rings [56], may indicate formation of a pseudo-lignin, which is known to having carbonyl functional group [40,51]. It should be noted that the structures of the Hibbert ketone type originating from the cleavage of $\beta-\mathrm{O}-4^{\prime}$ are unconjugated ketones as $\mathrm{C}=\mathrm{O}$ is located at $\mathrm{C}_{\beta}$ position [53]. It was not possible to confirm the depolymerization of $\beta-\mathrm{O}-4^{\prime}$ using FTIR because of the bands attributed to $\mathrm{C}_{\text {alkyl }}-\mathrm{O}$ ether vibrations (methoxyl and $\beta-\mathrm{O}-4^{\prime}$ ) at $1047-1004 \mathrm{~cm}^{-1}$ region overlaps with the cellulose $\mathrm{C}-\mathrm{O}$ valence vibrations in the range of $1060-1015 \mathrm{~cm}^{-1}$. SE pretreatment also led to reduction in intensity of a band at $1162 \mathrm{~cm}^{-1}$ representing $\mathrm{C}-\mathrm{O}-\mathrm{C}$ asymmetric valence vibration in hemicellulose [60]. Additional bands appeared at 1327 and $1114 \mathrm{~cm}^{-1}$ in steam-exploded birch, showing aromatic ring $\mathrm{C}-\mathrm{O}$ and $\mathrm{C}-\mathrm{H}$ in-plane deformation in $\mathrm{S}$ lignin units, respectively [61]. These signals could also relate to condensation of $G$ units at position $G_{5} 61_{]}$, which has similar structure as $\mathrm{S}$ units.

The FTIR analysis further demonstrated the removal of carbohydrates and enrichment of the lignin fraction in the HL after enzymatic hydrolysis of the pretreated birch (Additional file 1: Figure S1C). In comparison with the steam-exploded birch, the appearance of an additional weak band in $\mathrm{HL}$ at $880 \mathrm{~cm}^{-1}$, representing the aromatic $\mathrm{C}-\mathrm{H}$ out-of-plane bending, is due to the enrichment of lignin after enzymatic hydrolysis. The removal of cellulose was shown as reduction in intensities of the $\mathrm{C}-\mathrm{O}$ stretching at $1240 \mathrm{~cm}^{-1}$ and the $\mathrm{C}-\mathrm{O}$ valence vibration at $1045 \mathrm{~cm}^{-1}$ in HL. Because of cellulose removal, the weak bands at $1214 \mathrm{~cm}^{-1}(\mathrm{C}-\mathrm{C}$ and $\mathrm{C}-\mathrm{O}$ stretch in $\mathrm{G}$ condensed) and $1114 \mathrm{~cm}^{-1}(\mathrm{C}-\mathrm{H}$ stretch in $\mathrm{S}$ unit and/ or condensed-G units at position $G_{5}$ ) [61] became more strong in HL. This is consistent with the observed lignin structural modification seen by the NMR analysis.

The HL birch after AD (Additional file 1: Figure S1D) showed similar profiles as the original HL material, but lower intensities were observed for the bands at 1735$1710(\mathrm{C}=\mathrm{O}$ stretching in hemicelluloses and/or pseudolignin), 1325 (aromatic ring $\mathrm{C}-\mathrm{O}$ in $\mathrm{S}$ units and/or condensed- $\mathrm{G}$ units at position $\left.\mathrm{G}_{5}\right), 1214(\mathrm{C}-\mathrm{C}$ and $\mathrm{C}-\mathrm{O}$ stretch in $\mathrm{G}$ condensed), and $1114 \mathrm{~cm}^{-1}$ (aromatic ring $\mathrm{C}-\mathrm{H}$ stretch in $\mathrm{S}$ unit and/or condensed-G units at position $\mathrm{G}_{5}$ ) in the former. The reduction in intensity of these bands is consistent with the degradation of condensed-/ pseudo-lignin and removal of hemicelluloses shown by the HSQC NMR analysis.

\section{Py-GC/MS analysis}

Py-GC/MS analysis was applied to all the birch samples. As an example, the pyrogram of HL is shown in Fig. 5, illustrating the well-separated pyrolysis products derived from the lignin and carbohydrate components of $\mathrm{HL}$ birch. Similar pyrograms were produced and identified for all samples giving a total of 27 identified lignin pyrolysis products, including $4 \mathrm{H}$ units, $11 \mathrm{G}$ units, and $12 \mathrm{~S}$ units (Table 3). The relative proportion of lignin-derived pyrolysis products was calculated to determine the difference in lignin structure of the various birch samples

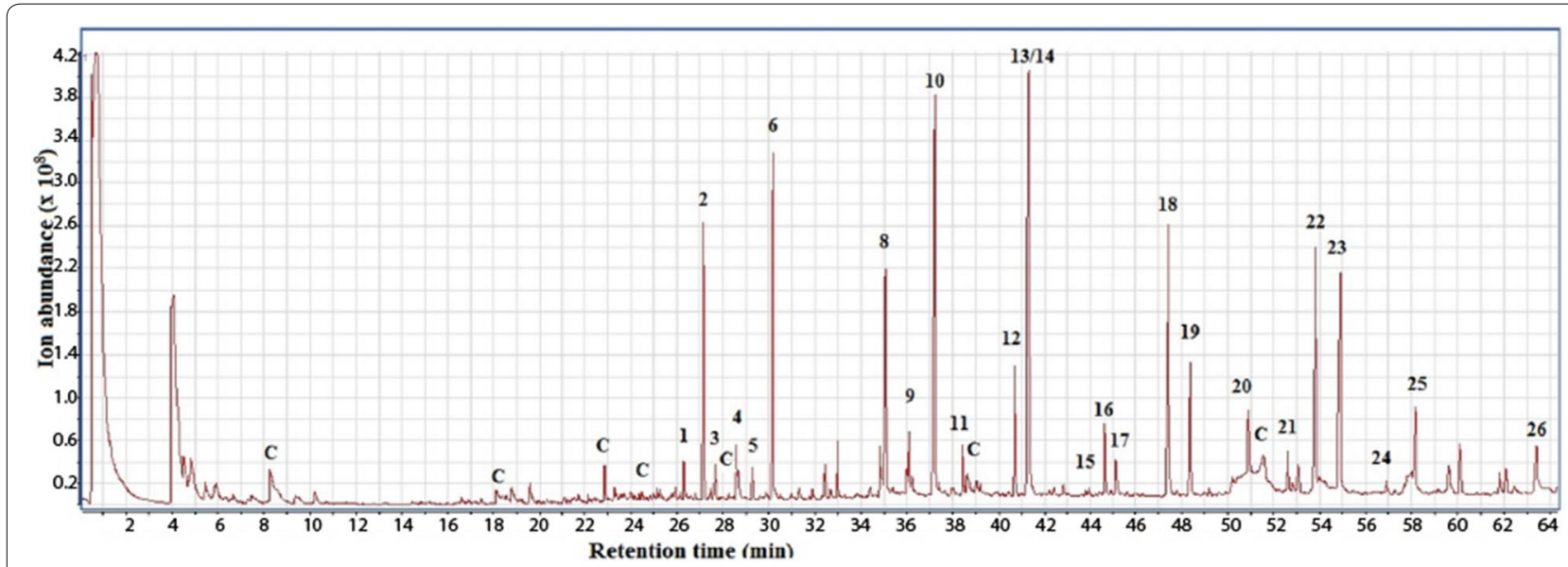

Fig. 5 Pyrograms of $\mathrm{HL}$ birch obtained at $600^{\circ} \mathrm{C}$. Peak identities and relative abundances of pyrolysis compounds released from $\mathrm{HL}$ birch and other birch samples are listed in Table 3 
Table 3 Relative abundance of lignin-derived pyrolysis products of birch samples at $600{ }^{\circ} \mathrm{C}$

\begin{tabular}{|c|c|c|c|c|c|c|}
\hline \multirow[t]{2}{*}{ Pyrolysis products } & \multirow[t]{2}{*}{ Peak no. } & \multirow[t]{2}{*}{$\mathrm{RT}(\min )$} & \multicolumn{4}{|c|}{ Relative abundance (\%) ${ }^{a}$} \\
\hline & & & Untreated birch & $\begin{array}{l}\text { Steam-exploded } \\
\text { birch }\end{array}$ & $\mathrm{HL}$ & $\mathrm{HL}$ after $\mathrm{AD}$ \\
\hline Phenol & 1 & 26.303 & 1.0 & 1.4 & 0.8 & 2.4 \\
\hline Guaicol & 2 & 27.141 & 3.8 & 6.9 & 6.1 & 8.8 \\
\hline Phenol,2-methyl & 3 & 27.658 & 0.6 & 0.9 & 0.8 & 1.3 \\
\hline p-Cresol & 4 & 28.417 & 3.7 & 1.6 & 0.7 & 1.8 \\
\hline Phenol,4-methoxy-3-methyl- & 5 & 29.285 & 1.3 & 0.7 & 0.8 & 0.8 \\
\hline Phenol,2-methoxy-4-methyl- & 6 & 30.149 & 4.2 & 7.0 & 9.0 & 12.8 \\
\hline Phenol,4-ethyl-2-methoxy- & 7 & 32.967 & 2.7 & 1.1 & 1.5 & 2.1 \\
\hline 2-Methoxy-4-vinylphenol & 8 & 35.035 & 5.2 & 6.5 & 6.2 & 10.9 \\
\hline Eugenol m/z 164 & 9 & 36.085 & 0.3 & 0.2 & 0.2 & 0.7 \\
\hline Phenol,2,6-dimethoxy- & 10 & 37.169 & 10.9 & 17.4 & 15.4 & 8.0 \\
\hline Phenol,2-methoxy-5-(1-propenyl),(E)- & 11 & 38.418 & 1.3 & 1.1 & 1.6 & 2.5 \\
\hline trans-Isoeugenol & 12 & 40.67 & 4.1 & 3.3 & 4.3 & 8.7 \\
\hline 1,2,4-Trimethoxybenzene $168 \mathrm{~m} / \mathrm{z}$ & 13 & 41.218 & 1.8 & 3.1 & 4.0 & 2.2 \\
\hline Vanillin $152 \mathrm{~m} / \mathrm{z}$ & 14 & 41.297 & 1.5 & 0.8 & 0.9 & 1.7 \\
\hline Phenol,2-methoxy-4-propyl- & 15 & 43.989 & 2.4 & 1.0 & 0.0 & 0.8 \\
\hline 5-tert-Butylpyrogallol & 16 & 44.665 & 1.2 & 1.2 & 2.4 & 0.9 \\
\hline Acetovanillone & 17 & 45.148 & 2.4 & 0.9 & 1.4 & 3.4 \\
\hline 3,5-Dimethoxyacetophenone & 18 & 47.385 & 11.1 & 11.6 & 11.2 & 9.1 \\
\hline Phenol,2,6-dimethoxy-4-(2-propenyl)- ${ }^{\mathrm{b}}$ & 19 & 48.361 & 4.4 & 3.8 & 4.8 & 3.3 \\
\hline Phenol,2,6-dimethoxy-4-(2-propenyl)- ${ }^{b}$ & 20 & 50.915 & 1.6 & 1.2 & 2.2 & 1.4 \\
\hline $\begin{array}{l}\text { 2-(2,5-Dimethoxy-4-ethylphenyl)ethyl- } \\
\text { amine, N-acetyl- }\end{array}$ & 21 & 52.649 & 1.4 & 1.2 & 1.4 & 0.9 \\
\hline Phenol,2,6-dimethoxy-4-(2-propenyl)- ${ }^{\mathrm{b}}$ & 22 & 53.788 & 9.2 & 7.3 & 9.5 & 7.1 \\
\hline Syringaldehyde & 23 & 54.833 & 12.0 & 9.9 & 10.3 & 4.8 \\
\hline Homosyringic acid & 24 & 56.93 & 5.4 & 2.7 & 0.0 & 0.0 \\
\hline Acetosyringone & 25 & 58.173 & 4.4 & 3.7 & 2.3 & 2.3 \\
\hline Sinapyl alcohol & 26 & 60.123 & 1.2 & 3.1 & 1.9 & 1.3 \\
\hline Sinapic aldehyde & 27 & 63.501 & 0.9 & 0.4 & 0.2 & 0.2 \\
\hline Total & & & 100.0 & 100.0 & 100.0 & 100.0 \\
\hline$H(\%)$ & & & 5.5 & 3.7 & 4.0 & 4.0 \\
\hline G (\%) & & & 29.3 & 29.4 & 31.9 & 53.1 \\
\hline S (\%) & & & 64.3 & 65.5 & 63.4 & 40.5 \\
\hline S/G ratio & & & 2.2 & 2.2 & 2.0 & 0.8 \\
\hline $\mathrm{Ph}-\mathrm{C} 1, \mathrm{C} 2 / \mathrm{Ph}-\mathrm{C} 3$ ratio & & & 0.7 & 0.9 & 0.9 & 1.2 \\
\hline Oxygenated side chain (\%) & & & 40.4 & 34.4 & 29.6 & 23.7 \\
\hline
\end{tabular}

a The peak areas of the lignin-derived pyrolysis products were normalized to $100 \%$

b Peaks 19, 20 and 22 are all assigned as the same compound by the NIST 11 MS library, and are likely isomers

(Table 3). The peaks marked with " $\mathrm{C}$ " in the pyrograms originated from cellulose and hemicelluloses degradation (e.g., 5-HMF, furfural, and levoglucosan) were not included in the calculations. In addition to the untreated and steam-exploded birch, the lignin-rich fractions (HL before and after AD) also gave rise to small amounts of carbohydrate-derived pyrolysis compounds.

As shown in Table 3, the main lignin pyrolysis products originating from untreated birch hardwood were $S$ and $\mathrm{G}$ units with an S/G ratio of 2.2. In comparison with NMR analysis, the $S / G$ ratio was slightly underestimated by $\mathrm{Py}-\mathrm{GC} / \mathrm{MS}$. Our results are consistent with a previous study, where the $S / G$ ratio in hardwood determined by $\mathrm{Py}-\mathrm{GC} / \mathrm{MS}$ was lower, possibly due to enhanced demethoxylation of S-type units during thermolysis [62]. The proportion of $\mathrm{H}$ type units reached less than $6 \%$ of all lignin-derived pyrolysis products, and was not detected by the NMR analysis. This difference is expected due to 


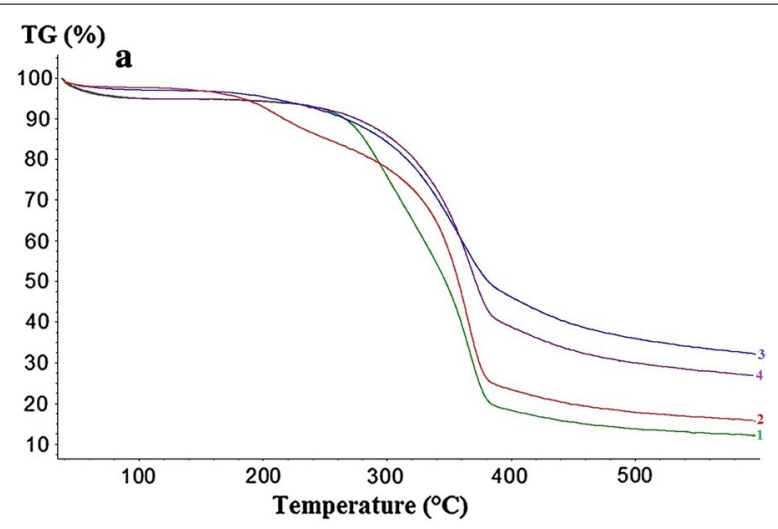

Gram Schmidt * $10-2$

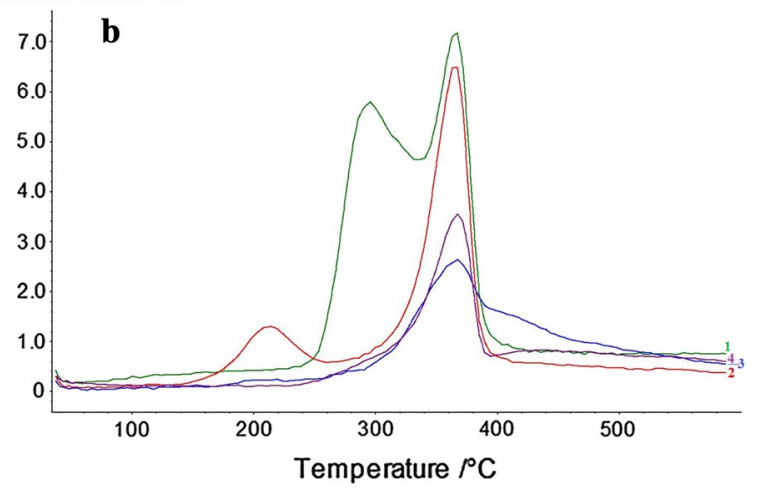

Fig. 6 STA analysis of thermal behavior of birch samples. Thermogravimetric (TG) (a) and the Gram Schmidt (GS) curves (b) of untreated (1), steam-exploded (2), HL (3), and HL birch after AD (4)

the higher sensitivity of mass spectrometry and the possibility for producing $\mathrm{H}$ type unit fragments originating from non-lignin components like aromatic amino acids during pyrolysis [30].

The effect of SE on lignin structure is clearly visible as the relative amounts of pyrolysis products between untreated and pretreated birch samples showed considerable differences (Table 3). In particular, the proportion of pyrolysis products with oxygen in the side chain (vanillin, acetovanillone, 3,5-dimethoxyacetophenone, homosyringic acid, syringaldehyde, sinapyl alcohol, and sinapic aldehyde) was lower in steam-exploded birch in comparison with untreated birch. This indicates the modification of oxygenated functional groups, mainly the $\beta-\mathrm{O}-4^{\prime}$ bond, resulting in lower content of pyrolysis products with oxygenated side chains in pretreated birch. Lower contents of oxygen-rich pyrolysis products were obtained from Kraft lignin as a result of the $\beta-O-4^{\prime}$ bond cleavage during Kraft cooking [63]. The increase in the ratio of phenylmethane and phenylethane units to phenylpropane units $\left(\mathrm{Ph}-\mathrm{C}_{1}, \mathrm{C}_{2} / \mathrm{Ph}-\mathrm{C}_{3}\right.$ ratio; Table 3$)$ after pretreatment further supports the cleavage and/or modification of part of the side-chain linkages of lignin substructures and agrees well with the condensed-/pseudo-lignin formation after pretreatment as confirmed by spectroscopy and SEM analysis (see below). It is not surprising that the ligninderived pyrolysis products of steam-exploded birch and $\mathrm{HL}$ are almost identical. The enzymatic treatment is mild and only degrades the polysaccharide fraction.

There was considerable difference between the pyrolysis products of HL before and after AD (Table 3). Notably, the $\mathrm{S} / \mathrm{G}$ ratio in $\mathrm{HL}$ after AD was substantially lower than the original HL, consistent with the S/G ratio reduction also seen by NMR analysis. This could be a result of an increase in G-type pyrolysis products due to the condensed-G-type lignin cleaves off and leaves the normal G-type lignin in the undigested solid material after AD.

\section{Thermal properties of birch by STA}

Figure 6 shows the thermogravimetric (TG) and Gram Schmidt (GS) curves from the simultaneous thermal analysis (STA) of the various birch samples. The initial slight weight loss for up to $100{ }^{\circ} \mathrm{C}$, mainly seen for the untreated birch and HL after $\mathrm{AD}$, is due to water evaporation (Fig. 6a). The thermal degradation profile of birch in the range of $200-400{ }^{\circ} \mathrm{C}$ was different after SE pretreatment, consistent with the changes observed in composition after pretreatment (Table 1). In comparison with untreated birch, the degradation process occurred earlier at a lower temperature for steamexploded birch; however, more carbonaceous residue remained after $500{ }^{\circ} \mathrm{C}$ for steam-exploded birch. This difference is also clearly illustrated in the GS curves, as presented in Fig. 6b. The pretreated birch showed a small mass loss at around $215{ }^{\circ} \mathrm{C}$, which was not observed for the untreated birch. This mass loss could be attributed to the volatile compounds formed from carbohydrates during the steam explosion pretreatment. The maximum thermal decomposition (TGmax) was around $365{ }^{\circ} \mathrm{C}$ for both untreated and pretreated birch, but an additional peak around $295{ }^{\circ} \mathrm{C}$ was observed in the former (Fig. 6b). It is known that hemicelluloses, cellulose, and lignin thermal degradation occurs in the temperature ranges of 200-300, 275-400, and $200-500{ }^{\circ} \mathrm{C}$, respectively. Therefore, TGmax is attributed to thermal degradation of mainly cellulose and part of lignin. The absence of mass loss at around $295{ }^{\circ} \mathrm{C}$, characteristics to hemicelluloses degradation, after birch pretreatment is consistent with the loss of some of hemicelluloses components during SE pretreatment (Table 1). The observed higher carbonaceous residue after SE pretreatment (TG curve, Fig. 6a) is consistent with the relatively higher content of lignin in pretreated material (Table 1). In general, thermal degradation of pure lignin yields about $30 \%$ char, whereas 

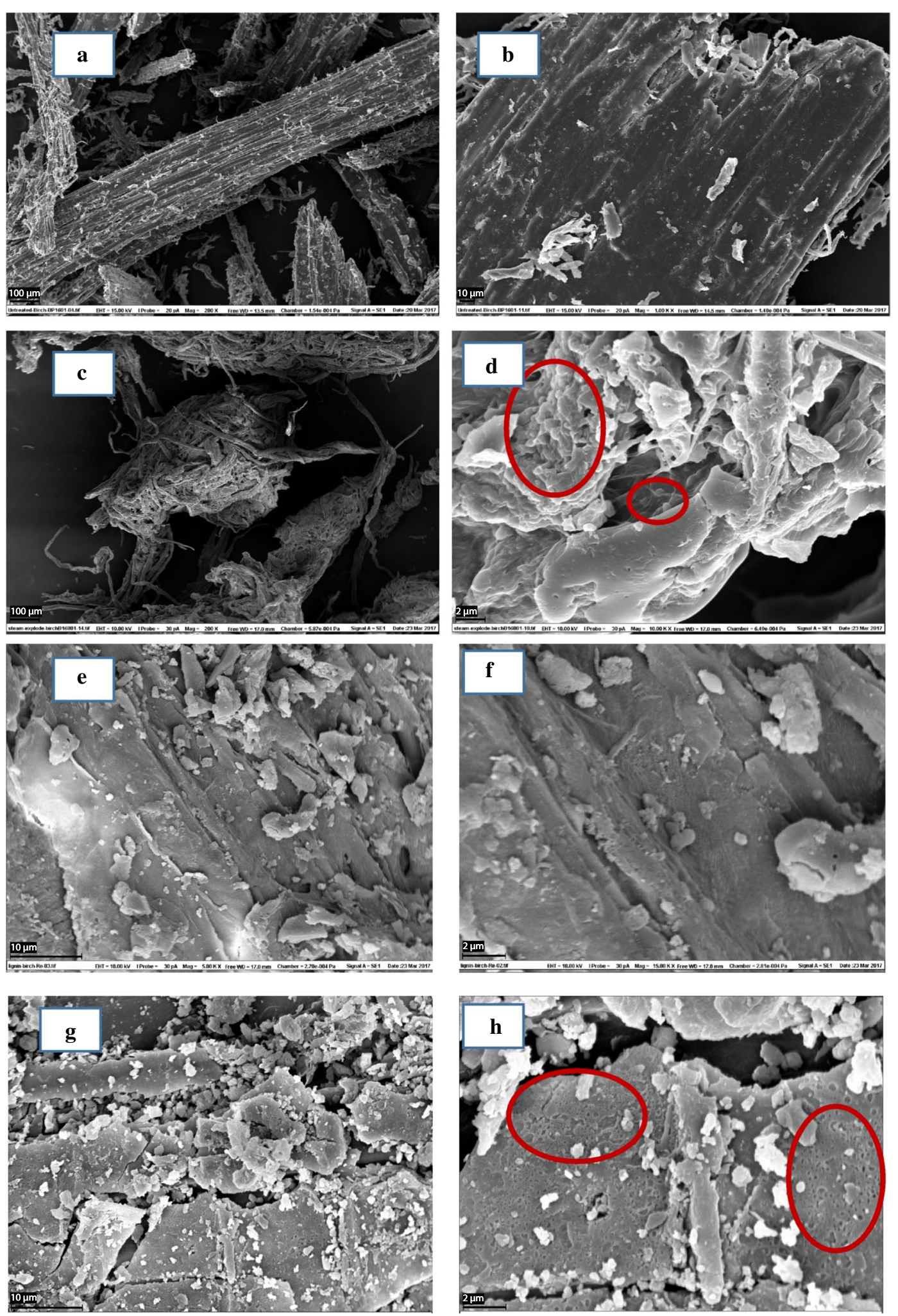

Fig. 7 SEM images showing the morphology of birch samples at low and high resolutions. Untreated (a, b), steam-exploded (c, d), HL (e, f) and $\mathrm{HL}$ birch after $\mathrm{AD}(\mathbf{g}, \mathbf{h})$. The droplets representing lignin re-orientation/pseudo-lignin formation (d) and honey-comb-like holes (h/ may represent microbial attack on the lignin surface) are marked with red circles 
cellulose and hemicellulose yield only about 5 and $5-10 \%$ residue, respectively [64].

The effect of enzymatic hydrolysis and $\mathrm{AD}$ on the thermal property of HL is clearly shown in the TG and GS curves (Fig. 6). The TGmax for both pretreated birch and HL was observed around $365{ }^{\circ} \mathrm{C}$, but it is lower in the latter due to the removal of cellulose by enzymatic hydrolysis. In comparison with the pretreated birch, the broader TGmax in HL stretching up to $500{ }^{\circ} \mathrm{C}$ (Fig. 6b), which shows that the lignin after enzymatic hydrolysis is resistant to thermal degradation. As expected, HL produced higher amount of carbonaceous residue. The TG profile (Fig. 6a) of the HL before and after AD was similar, but higher overall mass loss was observed after AD. The lower amount of carbonaceous residue after AD could be due to the change in lignin structure, particularly the anaerobic degradation of condensed-lignin and pseudo-lignin as confirmed by NMR, FTIR, and Py-GC/ MS analyses.

\section{Morphology characteristics of birch samples by SEM}

The changes in morphology of the birch samples after SE pretreatment, enzymatic saccharification, and $A D$ are presented in Fig. 7. These representative SEM images were taken from a collection of over ten images each for all birch samples at various magnifications. Untreated birch stands out with an intact and smooth surface (Fig. 7a, b). After SE pretreatment, the fibers were broken and formed a porous surface (Fig. 7c, d). Moreover, the higher resolution image of steam-exploded birch revealed formation of droplet on the surface of the material (Fig. 7d), which may be due to the deposition of pseudo-lignin on the surface of the pretreated material [40]. As expected, the major microfibrous cellulose structure was removed and the surface became smooth in HL due to the enzymatic hydrolysis of the carbohydrate component (Fig. 7e, f). Following AD, the HL was broken and formed several honey-comb-like holes on the surface of the material (Fig. $7 \mathrm{~g}, \mathrm{~h}$ ), which may be attributed to the modification of the surface by anaerobic microbes.

In summary, the NMR and FTIR analysis demonstrated degradation of pseudo-lignin, condensed-lignin, LCC and carbohydrates during AD. Py-GC/MS confirmed the degradation of condensed lignin. The higher weight loss measured by STA for the HL sample taken after AD indicated easier thermal breakdown of lignin deprived of condensed structures. SEM analysis showed that $\mathrm{HL}$ was broken into smaller pieces and formed several honey-comb-like holes on its surface, probably a result of microbial attack on HL during its anaerobic degradation. Overall, the degradable lignin structures, LCC, and carbohydrates fractions of HL had contributed to the methane production from $\mathrm{AD}$ of $\mathrm{HL}$.
In addition, the chemical analysis and biogas test of steam-exploded birch showed that hemicelluloses removal, lignin relocalization with some structural modification together with broken fiber and porous surface on steam-exploded materials may be responsible for reduction of biomass recalcitrance after SE, which ultimately enhanced the methane production from pretreated birch.

\section{Conclusions}

The lignin-rich material (HL) obtained after enzymatic extraction of carbohydrates has a potential to be used for biogas production. HL birch contained up to $80 \%$ lignin with condensed structure due to competing lignin depolymerization (mainly through cleavage of the abundant $\beta-\mathrm{O}-4^{\prime}$ inter-unit linkages) and re-condensation reactions during pretreatment. Pseudo-lignin also contributed to the Klason lignin content in HL. The results from biogas potential tests, NMR, Py-GC/ MS and FTIR analysis indicated that the carbohydrate fraction and part of the lignin fraction in HL birch were degraded during AD. Pseudo-lignin, condensed-lignin, benzyl ether, and phenylcoumaran were susceptible to $A D$, whereas $\beta-O-4^{\prime}$ and resinol were resistance to anaerobic microbial degradation. On the other hand, the remaining undigested lignin-rich residues after $\mathrm{AD}$ that has less pseudo and condensed-lignin structures and low carbohydrate impurity bears potential for further valorization. This study shows the benefits of using a combination of nylon bag techniques and advanced analytical techniques to study the degradation mechanisms of lignin during AD. It also demonstrated that utilization of HL residues after bioethanol production for biogas production may increase the output of energy carriers from lignocellulosic biomass.

\section{Additional file}

Additional file 1: Table S1. Assignments of ${ }^{13} \mathrm{C}-{ }^{1} \mathrm{H}$ correlation signals in the HSQC spectra of the lignin components in birch. Figure S1. FTIR spectra of untreated (A), steam-exploded (B), HL (C) and HL birch after AD (D).

\footnotetext{
Abbreviations

100Ar: 100 aromatic units $(\mathrm{H}+\mathrm{G}+\mathrm{S})$; 2D-HSQC NMR: two-dimensional ${ }^{1} \mathrm{H}-{ }^{13} \mathrm{C}$ heteronuclear single quantum coherence nuclear magnetic resonance spectroscopy; AD: anaerobic digestion; BE: benzyl ether linkages; CSTR: continuously stirred tank reactor; DM: dry matter; FTIR: Fourier transform infrared spectroscopy; G: guaiacyl lignin units; GC: gas chromatography; GS: Gram Schmidt; $H$ : $p$-hydroxyphenyl lignin units; HL: hydrolysis lignin; HPAEC-PAD: anion-exchange chromatography with pulsed amperometric detection; LCC lignin-carbohydrate complex linkages; LMW: lower molecular weight; MWL: milled wood lignin; $\mathrm{Ph}-\mathrm{C}_{1}$ : phenylmethane unit; $\mathrm{Ph}-\mathrm{C}_{2}$ : phenylethane unit; Ph- $C_{3}$ : phenylpropane unit; Py-GC/MS: pyrolysis-gas chromatography-mass spectrometry; S: syringyl lignin units; SE: steam explosion; SEM: scanning electron microscopy; STA: simultaneous thermal analysis; TCD: thermal conductivity detector; TG: thermogravimetric; TGmax: the maximum thermal decomposition; VS: volatile solids.
} 


\section{Authors' contributions}

DGM and SJH participated in the design of the study. DGM conducted the experiments and analyzed the data. JD conducted the simultaneous therma analysis (STA) analysis. DGM wrote the first draft of the manuscript, and all authors revised the manuscript. SJH participated in the design, coordination, and funding support of this study. All authors read and approved the final manuscript.

\section{Author details}

${ }^{1}$ Faculty of Chemistry, Biotechnology and Food Science, Norwegian University of Life Sciences, P.O. Box 5003, 1432 Ås, Norway. ${ }^{2}$ Norwegian Institute of Bioeconomy Research, P.O. Box 115, 1432 Ås, Norway.

\section{Acknowledgements}

We thank Ida Synnøve Aarum for her help with Py-GC/MS analysis and providing milled wood lignin (MWL) birch. We are grateful to Hilde Raanaas Kolstad for help with the SEM analysis at the NMBU Imaging Centre.

\section{Competing interests}

The authors declare that they have no competing interests.

\section{Availability of data and materials}

All data generated or analyzed during this study are included in this article and its additional file.

\section{Consent for publication}

Not applicable.

\section{Ethics approval and consent to participate}

Not applicable.

\section{Funding}

This study was financial supported by the Norwegian Research Council (Grant No. 243950, BioLiGas).

\section{Publisher's Note}

Springer Nature remains neutral with regard to jurisdictional claims in published maps and institutional affiliations.

Received: 6 September 2017 Accepted: 15 February 2018

Published online: 09 March 2018

\section{References}

1. Langholtz M, Downing M, Graham R, Baker F, Compere A, Griffith W, Boeman R, Keller M. Lignin-derived carbon fiber as a co-product of refining cellulosic biomass. SAE Int J Mater Manuf. 2014;7(1):115-21.

2. Stewart D. Lignin as a base material for materials applications: chemistry, application and economics. Ind Crops Prod. 2008;27(2):202-7.

3. Ragauskas AJ, Beckham GT, Biddy MJ, Chandra R, Chen F, Davis MF, Davison BH, Dixon RA, Gilna P, Keller M. Lignin valorization: improving lignin processing in the biorefinery. Science. 2014;344(6185):1246843.

4. Kalyani DC, Fakin T, Horn SJ, Tschentscher R. Valorisation of woody biomass by combining enzymatic saccharification and pyrolysis. Green Chem. 2017;19:3302-12.

5. Pu Y, Hu F, Huang F, Davison BH, Ragauskas AJ. Assessing the molecular structure basis for biomass recalcitrance during dilute acid and hydrothermal pretreatments. Biotechnol Biofuels. 2013;6(1):15.

6. Zheng Y, Zhao J, Xu F, Li Y. Pretreatment of lignocellulosic biomass for enhanced biogas production. Prog Energy Combust Sci. 2014;42:35-53.

7. Taherzadeh MJ, Karimi K. Pretreatment of lignocellulosic wastes to improve ethanol and biogas production: a review. Int J Mol Sci. 2008;9(9):1621-51.

8. Hendriks ATWM, Zeeman G. Pretreatments to enhance the digestibility of lignocellulosic biomass. Bioresour Technol. 2009;100(1):10-8.

9. Oliveira FMV, Pinheiro IO, Souto-Maior AM, Martin C, Gonçalves AR, Rocha GJM. Industrial-scale steam explosion pretreatment of sugarcane straw for enzymatic hydrolysis of cellulose for production of second generation ethanol and value-added products. Bioresour Technol. 2013;130:168-73.

10. Ali Shah F, Mahmood Q, Maroof Shah M, Pervez A, Ahmad Asad S. Microbial ecology of anaerobic digesters: the key players of anaerobiosis. Sci World J. 2014;2014:183752.

11. Hosseini SE, Wahid MA. Development of biogas combustion in combined heat and power generation. Renew Sustain Energy Rev. 2014;40:868-75.

12. Mulat DG, Mosbæk F, Ward AJ, Polag D, Greule M, Keppler F, Nielsen JL, Feilberg $\mathrm{A}$. Exogenous addition of $\mathrm{H} 2$ for an in situ biogas upgrading through biological reduction of carbon dioxide into methane. Waste Manag. 2017;68:146-56.

13. Theuretzbacher F, Lizasoain J, Lefever C, Saylor MK, Enguidanos R, Weran N, Gronauer A, Bauer A. Steam explosion pretreatment of wheat straw to improve methane yields: investigation of the degradation kinetics of structural compounds during anaerobic digestion. Bioresour Technol. 2015;179:299-305.

14. Benner R, Maccubbin A, Hodson RE. Anaerobic biodegradation of the lignin and polysaccharide components of lignocellulose and synthetic lignin by sediment microflora. Appl Environ Microbiol. 1984;47(5):998-1004.

15. Ko J-J, Shimizu Y, Ikeda K, Kim S-K, Park C-H, Matsui S. Biodegradation of high molecular weight lignin under sulfate reducing conditions: lignin degradability and degradation by-products. Bioresour Technol. 2009;100(4):1622-7.

16. DeAngelis KM, Allgaier M, Chavarria Y, Fortney $J$, Hugenholtz P, Simmons B, Sublette K, Silver WL, Hazen TC. Characterization of trapped lignindegrading microbes in tropical forest soil. PLOS ONE. 2011;6(4):e19306.

17. Young L, Frazer A. The fate of lignin and lignin-derived compounds in anaerobic environments. Geomicrobiol J. 1987;5(3-4):261-93.

18. Hackett W, Connors W, Kirk T, Zeikus J. Microbial decomposition of synthetic 14C-labeled lignins in nature: lignin biodegradation in a variety of natural materials. Appl Environ Microbiol. 1977;33(1):43-51.

19. Dittmar T, Lara RJ. Molecular evidence for lignin degradation in sulfatereducing mangrove sediments (Amazonia, Brazil). Geochim Cosmochim Acta. 2001;65(9):1417-28.

20. Bache R, Pfennig N. Selective isolation of Acetobacterium woodii on methoxylated aromatic acids and determination of growth yields. Arch Microbiol. 1981;130(3):255-61.

21. Cookson $L$. The site and mechanism of $14 C$-lignin degradation by Nasutitermes exitiosus. J Insect Physiol. 1988;34(5):409-14.

22. Angelidaki I, Alves M, Bolzonella D, Borzacconi L, Campos J, Guwy A, Kalyuzhnyi S, Jenicek P, Van Lier J. Defining the biomethane potential (BMP) of solid organic wastes and energy crops: a proposed protocol for batch assays. Water Sci Technol. 2009;59(5):927-34

23. Vivekanand V, Olsen EF, Eijsink VGH, Horn SJ. Effect of different steam explosion conditions on methane potential and enzymatic saccharification of birch. Bioresour Technol. 2013;127:343-9.

24. Holliger C, Alves M, Andrade D, Angelidaki I, Astals S, Baier U, Bougrier C, Buffiere P, Carballa M, de Wilde V, et al. Towards a standardization of biomethane potential tests. Water Sci Technol. 2016;74(11):2515-22.

25. Valente TNP, Detmann E, Sampaio CB. Review: recent advances in evaluation of bags made from different textiles used in situ ruminal degradation. Can J Anim Sci. 2015:95(4):493-8.

26. Qrskov E, Hovell F, Mould F. The use of the nylon bag technique for the evaluation of feedstuffs. Anim Prod. 1980;5:195-213.

27. Sette $M$, Wechselberger $R$, Crestini C. Elucidation of lignin structure by quantitative 2D NMR. Chem A Eur J. 2011;17(34):9529-35.

28. Balakshin M, Capanema E, Gracz H, Chang H-M, Jameel H. Quantification of lignin-carbohydrate linkages with high-resolution NMR spectroscopy. Planta. 2011:233(6):1097-110.

29. Wen J-L, Sun S-L, Xue B-L, Sun R-C. Quantitative structures and thermal properties of birch lignins after ionic liquid pretreatment. J Agric Food Chem. 2013;61(3):635-45.

30. Ralph J, Hatfield RD. Pyrolysis-GC-MS characterization of forage materials. J Agric Food Chem. 1991;39(8):1426-37.

31. Galletti GC, Bocchini P. Pyrolysis/gas chromatography/mass spectrometry of lignocellulose. Rapid Commun Mass Spectrom. 1995;9(9):815-26.

32. Ke J, Laskar DD, Singh D, Chen S. In situ lignocellulosic unlocking mechanism for carbohydrate hydrolysis in termites: crucial lignin modification. Biotechnol Biofuels. 2011:4(1):17. 
33. Aarum I, Devle H, Ekeberg D, Horn SJ, Stenstrøm Y. The effect of flash pyrolysis temperature on compositional variability of pyrolyzates from birch lignin. J Anal Appl Pyrolysis. 2017;127(Supplement C):211-22.

34. Munir S, Daood SS, Nimmo W, Cunliffe AM, Gibbs BM. Thermal analysis and devolatilization kinetics of cotton stalk, sugar cane bagasse and shea meal under nitrogen and air atmospheres. Bioresour Technol. 2009;100(3):1413-8.

35. Barneto AG, Hernández RB, Berenguer JM. Thermogravimetric characterization of eucalyptus wood. O PAPEL. 2011;72(7):53-6.

36. Sluiter A, Hames B, Ruiz R, Scarlata C, Sluiter J, Templeton D, Crocker D. Determination of structural carbohydrates and lignin in biomass. Lab Anal Proced. 2008;1617:1-6.

37. APHA. Standard methods for the examination of water and wastewater. 19th ed. Washington, DC: American Public Health Association; 1995.

38. Auxenfans T, Crônier D, Chabbert B, Paës G. Understanding the structural and chemical changes of plant biomass following steam explosion pretreatment. Biotechnol Biofuels. 2017;10(1):36.

39. Li J, Henriksson G, Gellerstedt G. Carbohydrate reactions during hightemperature steam treatment of aspen wood. Appl Biochem Biotechnol. 2005;125(3):175-88.

40. Hu F, Jung S, Ragauskas A. Pseudo-lignin formation and its impact on enzymatic hydrolysis. Bioresour Technol. 2012;117:7-12.

41. Vivekanand V, Ryden P, Horn SJ, Tapp HS, Wellner N, Eijsink VGH, Waldron KW. Impact of steam explosion on biogas production from rape straw in relation to changes in chemical composition. Bioresour Technol. 2012;123(Supplement C):608-15.

42. Vivekanand V, Olsen EF, Eijsink VGH, Horn SJ. Methane potential and enzymatic saccharification of steam-exploded bagasse. BioResources. 2014;9:1311-24

43. Theuretzbacher F, Blomqvist J, Lizasoain J, Klietz L, Potthast A, Horn SJ, Nilsen PJ, Gronauer A, Passoth V, Bauer A. The effect of a combined biological and thermo-mechanical pretreatment of wheat straw on energy yields in coupled ethanol and methane generation. Bioresour Technol. 2015;194(Supplement C):7-13.

44. Kreuger E, Sipos B, Zacchi G, Svensson S-E, Björnsson L. Bioconversion of industrial hemp to ethanol and methane: the benefits of steam pretreatment and co-production. Bioresour Technol. 2011;102(3):3457-65.

45. Liu Y, Xu J, Zhang Y, Yuan Z, He M, Liang C, Zhuang X, Xie J. Sequential bioethanol and biogas production from sugarcane bagasse based on high solids fed-batch SSF. Energy. 2015;90(Part 1):1199-205.

46. Kalyani DC, Zamanzadeh M, Müller G, Horn SJ. Biofuel production from birch wood by combining high solid loading simultaneous saccharification and fermentation and anaerobic digestion. Appl Energy. 2017;193:210-9.

47. Dererie DY, Trobro S, Momeni MH, Hansson H, Blomqvist J, Passoth V, Schnürer A, Sandgren M, Ståhlberg J. Improved bio-energy yields via sequential ethanol fermentation and biogas digestion of steam exploded oat straw. Bioresour Technol. 2011;102(6):4449-55.

48. Sasaki K, Morita M, Hirano S-I, Ohmura N, Igarashi Y. Effect of adding carbon fiber textiles to methanogenic bioreactors used to treat an artificial garbage slurry. J Biosci Bioeng. 2009;108(2):130-5.

49. Sasaki K, Sasaki D, Morita M, Hirano S-I, Matsumoto N, Ohmura N, Igarashi Y. Efficient treatment of garbage slurry in methanogenic bioreactor packed by fibrous sponge with high porosity. Appl Microbiol Biotechnol. 2010;86(5):1573-83.

50. Rencoret J, del Río JC, Gutiérrez A, Martínez ÁT, Li S, Parkås J, Lundquist K. Origin of the acetylated structures present in white birch (Betula pendula Roth) milled wood lignin. Wood Sci Technol. 2012;46(1):459-71.

51. Sannigrahi P, Kim DH, Jung S, Ragauskas A. Pseudo-lignin and pretreatment chemistry. Energy Environ Sci. 2011;4(4):1306-10.

52. Heikkinen H, Elder T, Maaheimo H, Rovio S, Rahikainen J, Kruus K, Tamminen T. Impact of steam explosion on the wheat straw lignin structure studied by solution-state nuclear magnetic resonance and density functional methods. J Agric Food Chem. 2014;62(43):10437-44.

53. Li J, Henriksson G, Gellerstedt G. Lignin depolymerization/repolymerization and its critical role for delignification of aspen wood by steam explosion. Bioresour Technol. 2007;98(16):3061-8.

54. Wang $\mathrm{C}, \mathrm{Li} \mathrm{H}, \mathrm{Li}$ M, Bian J, Sun R. Revealing the structure and distribution changes of Eucalyptus lignin during the hydrothermal and alkaline pretreatments. Sci Rep. 2017;7:593.

55. Kajikawa H, Kudo H, Kondo T, Jodai K, Honda Y, Kuwahara M, Watanabe T. Degradation of benzyl ether bonds of lignin by ruminal microbes. FEMS Microbiol Lett. 2000;187(1):15-20.

56. Zhao J, Xiuwen W, Hu J, Liu Q, Shen D, Xiao R. Thermal degradation of softwood lignin and hardwood lignin by TG-FTIR and Py-GC/MS. Polym Degrad Stab. 2014;108:133-8,

57. Wang C, Xiong Y, Fan B, Yao Q, Wang H, Jin C, Sun Q. Cellulose as an adhesion agent for the synthesis of lignin aerogel with strong mechanical performance, sound-absorption and thermal Insulation. Sci Rep. 2016;6:32383.

58. Lupoi JS, Singh S, Parthasarathi R, Simmons BA, Henry RJ. Recent innovations in analytical methods for the qualitative and quantitative assessment of lignin. Renew Sustain Energy Rev. 2015;49:871-906.

59. Schwanninger M, Rodrigues JC, Pereira H, Hinterstoisser B. Effects of short-time vibratory ball milling on the shape of FT-IR spectra of wood and cellulose. Vib Spectrosc. 2004;36(1):23-40.

60. de Souza Moretti MM, Bocchini-Martins DA, Nunes CDCC, Villena MA, Perrone OM, da Silva R, Boscolo M, Gomes E. Pretreatment of sugarcane bagasse with microwaves irradiation and its effects on the structure and on enzymatic hydrolysis. Appl Energy. 2014;122:189-95.

61. Faix O. Classification of lignins from different botanical origins by FT-IR spectroscopy. Holzforsch International J Biol Chem Phys Technol Wood. 1991;45:21.

62. Liang Y, Lei B, Zhong H-T, Feng Y-H, Qu J-P. A promising screw-extrusion steam explosion pretreatment process: effects on the morphological and structural features of Eucalyptus woodchips. RSC Adv. 2016;6(111):109657-63.

63. Kim J-Y, Oh S, Hwang H, Kim U-J, Choi JW. Structural features and thermal degradation properties of various lignin macromolecules obtained from poplar wood (Populus albaglandulosa). Polym Degrad Stab. 2013;98(9):1671-8.

64. Sebestyén Z, Jakab E, May Z, Sipos B, Réczey K. Thermal behavior of native, washed and steam exploded lignocellulosic biomass samples. J Anal Appl Pyrol. 2013;101:61-71.

\section{Submit your next manuscript to BioMed Central and we will help you at every step:}

- We accept pre-submission inquiries

- Our selector tool helps you to find the most relevant journal

- We provide round the clock customer support

- Convenient online submission

- Thorough peer review

- Inclusion in PubMed and all major indexing services

- Maximum visibility for your research

Submit your manuscript at www.biomedcentral.com/submit
BioMed Central 